\title{
Energy planning for an eco-city based on a distributed energy network
}

\author{
Xiaojun Zhu' ${ }^{1}$, Jianhua Zhu ${ }^{1 *}$, Bencheng Wu' ${ }^{1}$, Minsheng Liu ${ }^{2,5}$, Guoqing Wang ${ }^{2,5^{*}}$, Zhenqi Zhu ${ }^{2,5}$, \\ Zhongxue Gan', Jing Zhang ${ }^{3}$ and Chuizhou Meng ${ }^{4,5^{*}}$
}

\begin{abstract}
Background: In China, traditional energy planning is subordinate to city planning, with a primary purpose of meeting the energy demand in urban areas by planning and designing an energy system. However, most of the current energy planning in China pertains to a low-efficient system and proves to be unfriendly to the environment, which is no longer appropriate for the future development of modern industrial parks and cities.

Methods: A combined cooling, heating, gas and power energy network with distributed cogeneration units and renewable energy sources provides an effective solution to the related problems. In this paper, a new energy planning method for the Eco-City is proposed, which is based on a Distributed Energy Network (DEN) system. The designed method of a four-stage energy integration mode is implemented, which includes prediction of the energy demand, optimization of the energy utilization, matching of the energy supply and the recovery side. Based on the planning and designing of the DEN, the technical and economic analysis draw reasonable results.
\end{abstract}

Results: As implemented in the practical case of the Sino-German Eco-Park, the procedure of the proposed energy planning method is comprehensively explained. Finally, by reviewing the planning, design and operation, the current state and problems of the Sino-German Eco-Park are described.

Conclusions: A new energy design for Eco-Parks is developed as a result of a thorough analysis of the planning process, which integrates city planning and energy planning together and provides energy solutions for high-level cities and industrial parks. The four-stage integrated energy model provides a guideline for the entire process and its detailed steps. Relevant experiences and lessons from the energy planning of the Sino-German Eco-Park are of significance for supporting similar projects in the future.

Keywords: Distributed energy network (DEN), Eco-City, Energy planning, City planning, Micro-grid, Four-stage integration, Sino-German Eco-Park

*Correspondence: secondzhu@sina.com; wangguoqinga@enn.cn; 2018108@hebut.edu.cn

${ }^{1}$ College of Chemical Engineering and Environment, China University

of Petroleum-Beijing, Beijing 102249, China

2 ENN Science \& Technology Ltd, Langfang 065001, China

${ }^{4}$ School of Mechanical Engineering, Hebei University of Technology, Tianjin 300130, China

Full list of author information is available at the end of the article

\section{Introduction}

With the progression of human civilization, people have always had and will consistently have new higher demands for a more comfortable life with better living environments, which requires large amounts of energy of different quality and quantity. However, in China, with the rapid development of urbanization due to the growing urban population, many problems arise because of the current unreasonable energy structure, such as fog haze, garbage and wastewater. At present, serious air pollution exists in most eastern, central, southern and original author(s) and the source, provide a link to the Creative Commons licence, and indicate if changes were made. The images or other third party material in this article are included in the article's Creative Commons licence, unless indicated otherwise in a credit line to the material. If material is not included in the article's Creative Commons licence and your intended use is not permitted by statutory regulation or exceeds the permitted use, you will need to obtain permission directly from the copyright holder. To view a copy of this licence, visit http://creativecommons.org/licenses/by/4.0/. The Creative Commons Public Domain Dedication waiver (http://creativeco mmons.org/publicdomain/zero/1.0/) applies to the data made available in this article, unless otherwise stated in a credit line to the data. 
northeastern regions of China. One of the main causes of the environmental problems is the pollutants from emissions, such as $\mathrm{SO}_{2}$ and $\mathrm{NO}_{x}$, which have been generated in the process of utilizing energy. If the energy-related problems cannot be solved promptly and effectively, the situation of the environmental pollution will become difficult to change in the long term [1].

Recently, renewable energy and distributed energy system (DES) have drawn more and more attention all over the world [2]. Renewable energy is collected from renewable resources, which are naturally replenished, such as sunlight, wind, rain, and tide wave and geothermal heat [3]. They are all environmentally friendly and widely distributed, and are characterized by little pollution and large reserves, which is considered to be of great significance for solving serious environmental problems such as air pollution that is caused by the combustion of fossil fuels [4]. Renewable energy plays an important role in ensuring energy supply and sustainable economic development, and China is rich in hydropower, wind, and solar and other renewable resources. Considering the urgent situation of current energy system development in China, it is important to actively develop and utilize renewable energy in the future. However, renewable energy has its own disadvantages due to its limited amounts and its intermittent and unstable rate of incidence and low energy density. Because its distribution is scattered, renewable energy is more suitable for localized utilization.

A DES has many advantages, such as fuel diversification, networking mode, intelligent control, information management, and environmental performance. It is one of the important energy technologies in the world [5]. Compared with the evolution process of the DES in America, Japan and Europe, the development of distributed energy in China, both from policy and technology, lags behind those in developed countries. Thus, there is a strong practical need to make great efforts to promote and apply the DES in China [6].

Combining the DES with renewable energy, might not only solve the problems of the small scale and the intermittent uncertainty and low energy density for renewable energy, but also add the advantages of efficiency and stability from DES. Thus, a localized energy balance could be achieved through multi-energy integration, which is a promising direction in the development of a future energy system in China.

\section{Methodology}

Energy is indispensable for modern cities, and the rapid development of cities is often accompanied by a large consumption of energy, so that the designing and planning of energy systems for cities with different sizes,

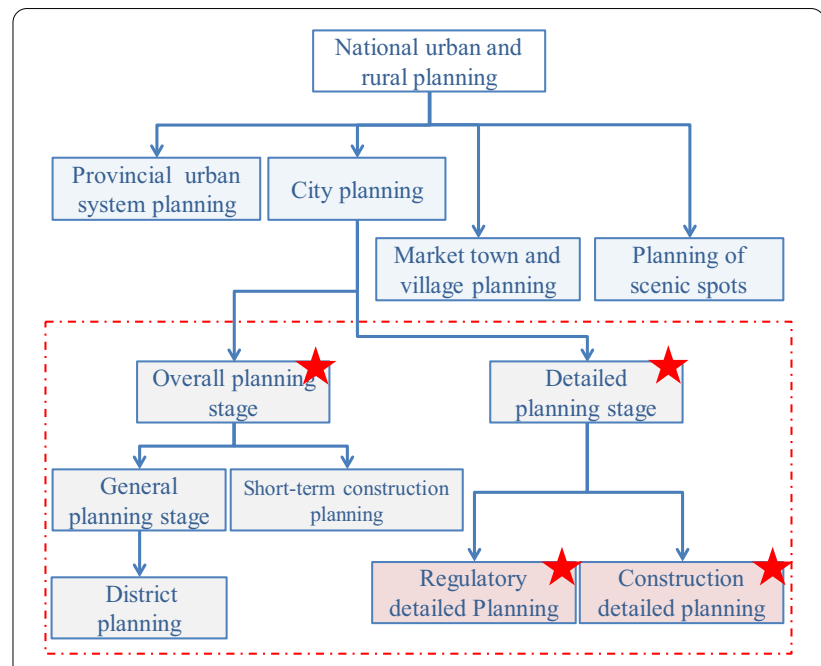

Fig. 1 Traditional Chinese urban and rural planning systems

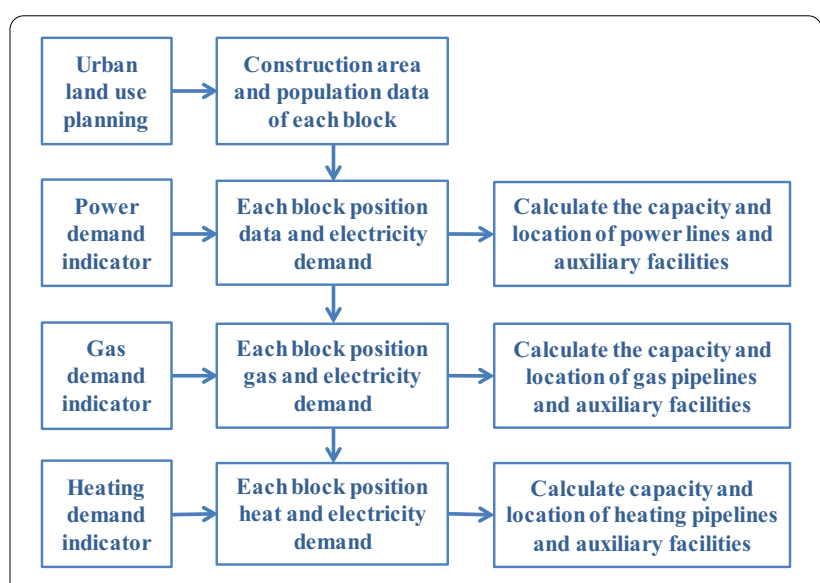

Fig.2 Traditional Chinese energy planning

life styles and development patterns are becoming very important in China.

\section{Energy planning and city planning}

In China, there is no a specific guiding principle for planning of an energy system, and the current city planning is insufficient for solving the problems encountered in the construction of the energy system.

For instance, as shown in Fig. 1, in China, the traditional urban and rural planning systems have only a few regulations with regard to the method and details of energy planning, and there is no universal standard and model that should be used. Traditional urban energy planning should be divided into regulatory detailed planning and construction detailed planning. As illustrated in Fig. 2, the power, gas, heating and other energy departments calculate the users' demand 
according to their own historical experience indicators and arrange various energy supply facilities independently from each other. Due to the lack of connection between multiple energy departments, the following problems appear to remain unsolved so far:

- Contradiction between energy planning and environmental protection;

- Difficulties in coordinating and integrating different energy projects;

- Planning based on qualitative methods is lacking detailed quantitative calculations.

It is significant to rethink the planning method of a city and shift it gradually from the traditional urban expansion-planning mode to a new mode that includes energy optimization and utilization with a definition of its boundaries and an optimization of the spatial structure of city planning, and seek an environmentally friendly and sustainable energy solution.

Figure 3 shows the parallel development process of city planning and energy planning, and there are many items of coordination and constraints between city planning and energy planning. On the precondition of environmentally friendly energy and energy efficiency, it is mainly composed of regional energy load forecasting and the design of distributed energy station and energy network. The new energy planning method has the following advantages:

- Taking the ecological system as the topical subject, which focuses on the implementation of energy-saving and environmental protection;
- Planning the multi-energy resources by different departments as a whole, and standardizing the planning and designing process;

- Digitizing energy planning by a quantitative index to guide practical implementation.

\section{Overall process of energy planning}

By taking into account the satisfaction of future energy needs, this energy planning intends to optimize the effective combination of various energy sources, in order to meet a specific energy demand. It is guided by the technical, social and economic criteria for a given region, i.e., the quantitative criteria for the exploitation of renewable energy sources concerning the actual situation of the region $[7,8]$. In light of energy production, a smart energy system should be developed by integrating as much energy from fluctuating renewable sources and scarce energy resources as is efficient and possible [9]. A recently emerging and promising energy supply network based upon a residential-scale micro-generation by combining a micro-heat and power (CCHP) system was proposed, and the interchange of electric energy could take place among the members within the domestic micro-grid, which is connected to the main electric grid for potential power interchange. Heat interchange within the subgroups of the whole micro-grid was also proposed [10]. In light of energy utilization, the energy savings by end users and district heating expansion, which were combined in the existing energy system, can also improve its overall energy efficiency [11]. In addition, there is an energy-sharing possibility among a cluster of buildings, in which each building generates both heat and electricity by using micro-energy generation technology and shares both types of energy with other buildings. The comparison of energy consumption in the separate and shared

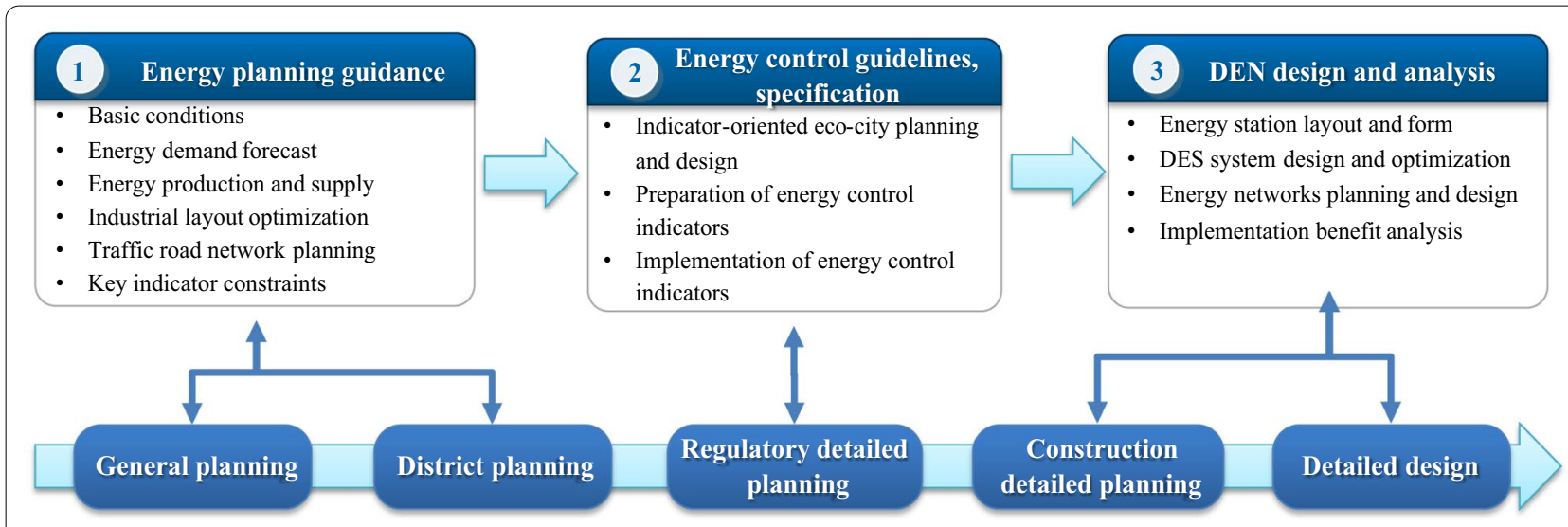

Fig.3 Parallel development process of energy planning and city planning 
cases has shown that the energy-sharing case has the advantage of energy management within boundaries [12]. Most of the present research studies have been based on energy demand analysis of end users or the optimization of energy supply systems. However, so far there has been no report on a systematic analysis method including a feasible analysis procedure. In this paper, we would like to propose a novel analysis method by using a systematic analysis procedure. Figure 4 shows a typical structure diagram of a distributed energy network (DEN) system. The DEN system is a new type of intelligent energy network system, which evolved from the DES, by combining networks of both energy and information. The DEN system is connected to the smart grid, the natural gas network and the regional heating network. At the same time, a variety of renewable energy sources in the region and natural gas are connected with end users in a distributed way, through the coordinated control of material flow, energy flow and information flow. The technology of a DEN is complicated, as it combines multiple techniques of renewable technology, micro-grid technology and information technology.

As shown in Fig. 5, the entire procedure starts from general planning in the city, which provides all the basic information, including the contents of various energy engineering plans, environmental constraint indicators and possible locations of energy facilities. There are three steps, firstly, analyzing the local resources, which includes the investigation of geothermal energy, solar energy, wind energy, etc. The investigation aims to better analyze the renewable energy that is locally available. Secondly, natural gas, electricity, heat and available excess energy around the planning area, which provides much help for the energy supply mode and energy supply

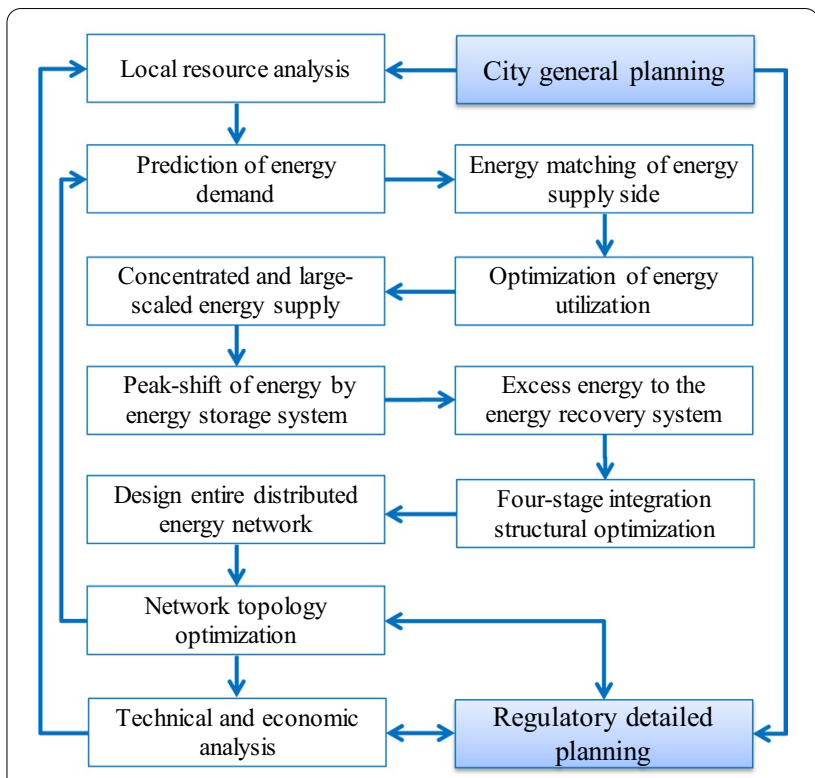

Fig. 5 The constraints of city planning in energy planning

system design, should be analyzed. Thirdly, the requirements of other planning, such as the industrial planning, traffic planning and urban land planning should be combined. These requirements are often the constraints for the entire planning of DENs.

The second procedure is to predict the energy demand, optimize the energy utilization and match the energy supply side. The purpose is to predict and optimize the energy load, which includes the analysis of industrial energy demand, building energy demand and traffic energy demand. The basic energy demand curve of the whole region will be obtained via a regional energy load

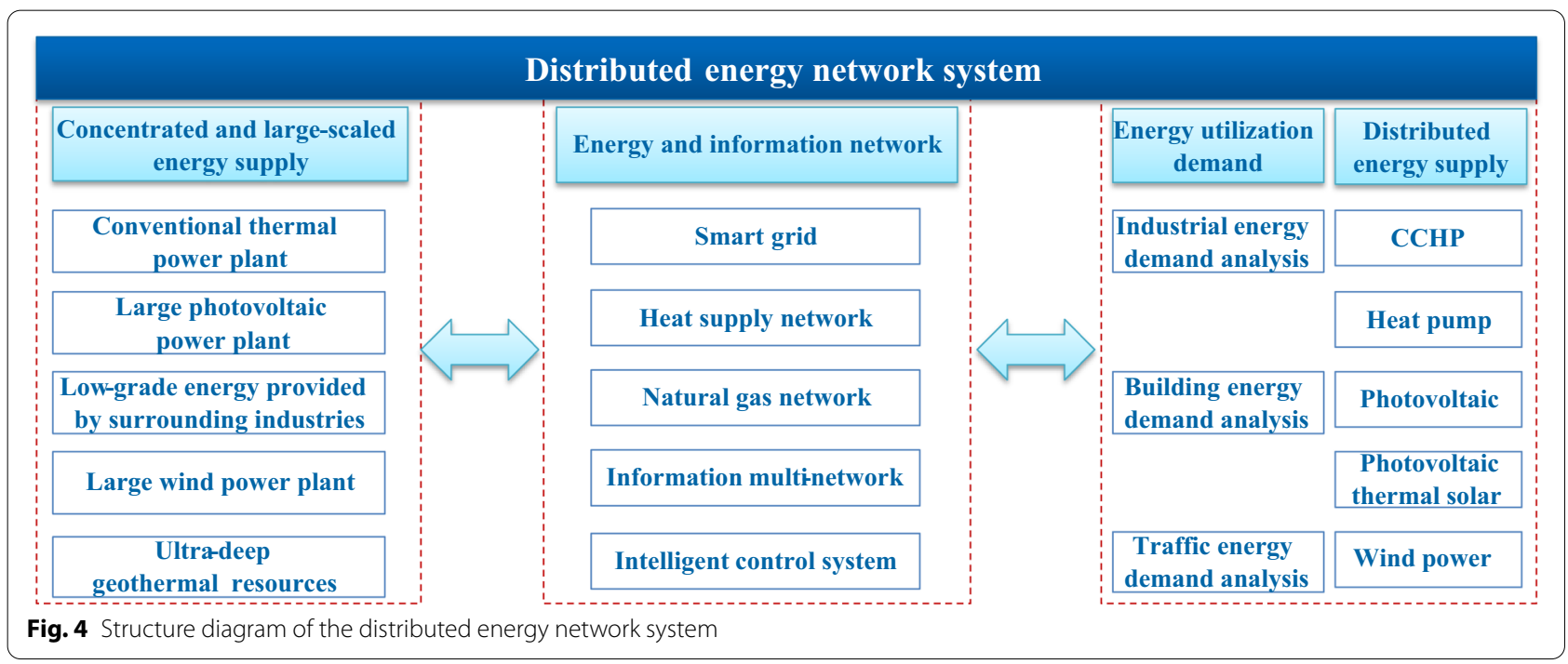


prediction. From a time and space point of view, these energy loads could be optimized in order to reduce the overall load demand by superimposing different types of an energy demand curve to further flatten the overall load curve, which provides better conditions for the subsequent design of the energy system. Next, distributed energy stations are designed based upon the energy load demand of different functional block areas, by using advanced distributed energy equipment such as CCHP, heat pumps, solar power and wind power, etc. It should be noted that the process of the DES design could only satisfy the basic demands of the energy load to ensure an appropriate equipment utilization time, since a low-cost energy storage system has been adopted to replace the peak area of the load curve and the excess energy produced by the city and industry.

The third procedure is to design and optimize the entire DEN. The whole energy system needs to be retrofitted to reach an energy balance for the entire energy system. The topology of the entire energy network is optimized by continuously adjusting the location of the DES to minimize operating costs and investment of the energy network. In the end, the DEN is set up by interconnecting smart grid, thermal network, natural gas network and the information control network.

Finally, the technical and economic analysis is carried out based upon various key indicators, to help us make final decisions for the project. These indicators include environmental indicators, energy-efficiency indicators and economic indicators. If the result is found to be inconsistent with the indicators in the regulatory detailed planning, it is necessary to return to the first step and redesign the local renewable energy resource analysis. In case one is still unable to meet the specified economic target after the technical and economic analysis of the whole project, it would be necessary to return to the first step and carry out the planning and designing of the entire DEN system again. Reducing the energy system from a high-cost investment unit, would help ensure that the economic indicators of the whole project could reach the preset expectation.

\section{Approach of four-stage integration in DEN systems}

Recently, city planners have begun to realize the importance of the tradeoffs between the limitations to CHP plant size and the performance of the overall energy system. The results vary with city scale, and for large cities, the losses incurred by using a single large CHP unit instead of multiple smaller units might be a significant factor. Furthermore, it will lead to higher initial investment than a conventional energy system [13]. On the other hand, in city communities, micro-grids with distributed cogeneration units and renewable energy sources provide an effective solution plan to the energyrelated problems of increasing energy demand, higher energy costs, energy supply safety, and environmental concerns. It also depends on the climatic zone, energy demand profiles, local energy price system and available renewable energy sources of the city or community. The performance of a CCHP micro-grid from the technical, economic and environmental point of view is closely dependent on the design and energy management of the micro-grid [14]. More importantly, it is necessary to consider the power, natural gas and thermal systems comprehensively and provide a reasonable planning and design principle as well as method for guidance.

Figure 6 depicts a schematic diagram of a typical fourstage integrated energy model. In this model, the entire energy planning process is divided into four stages, i.e., energy production and conversion, energy storage and transportation, energy utilization and energy recovery stage. In addition to these four stages, it requires an energy matching stage, which is responsible for upgrading the energy quality. For example, the heat pump can extract low-grade heat energy from the environment and then convert it to high-grade heat energy, but will consume higher-grade power. With consideration given to mutual influence and coordination between the four stages and the matching stage, a highly efficient DEN system can be set up.

The typical setup of a four-stage integrated energy model can be described in detail as follows: firstly, the energy utilization stage should be optimized by balancing the energy usage of different types of customers in time and space dimensions. Secondly, the production and energy conversion stage should be designed with priority given to the usage of renewable energy followed by clean natural gas, in order to achieve an optimized combination of different energy components with a reasonable matching of the capacity of the energy utility. Thirdly, the recovered energy stage as well as the recycle of the waste heat from nearby industry should be taken into account, in order to improve the quality of these low-grade heat sources and return them to the energy system. Finally, the energy storage and transportation stage should be designed, in order to respond to the imbalance of distributed energy in time and space and to the fluctuation of the energy price. Through the four-stage integrated energy system described above, a complete DEN system could be established.

\section{A case study}

In China, the energy infrastructure has developed alongside urban construction, and once established, had limited capacity for change. A well-designed energy planning plays an important role in the overall healthy 


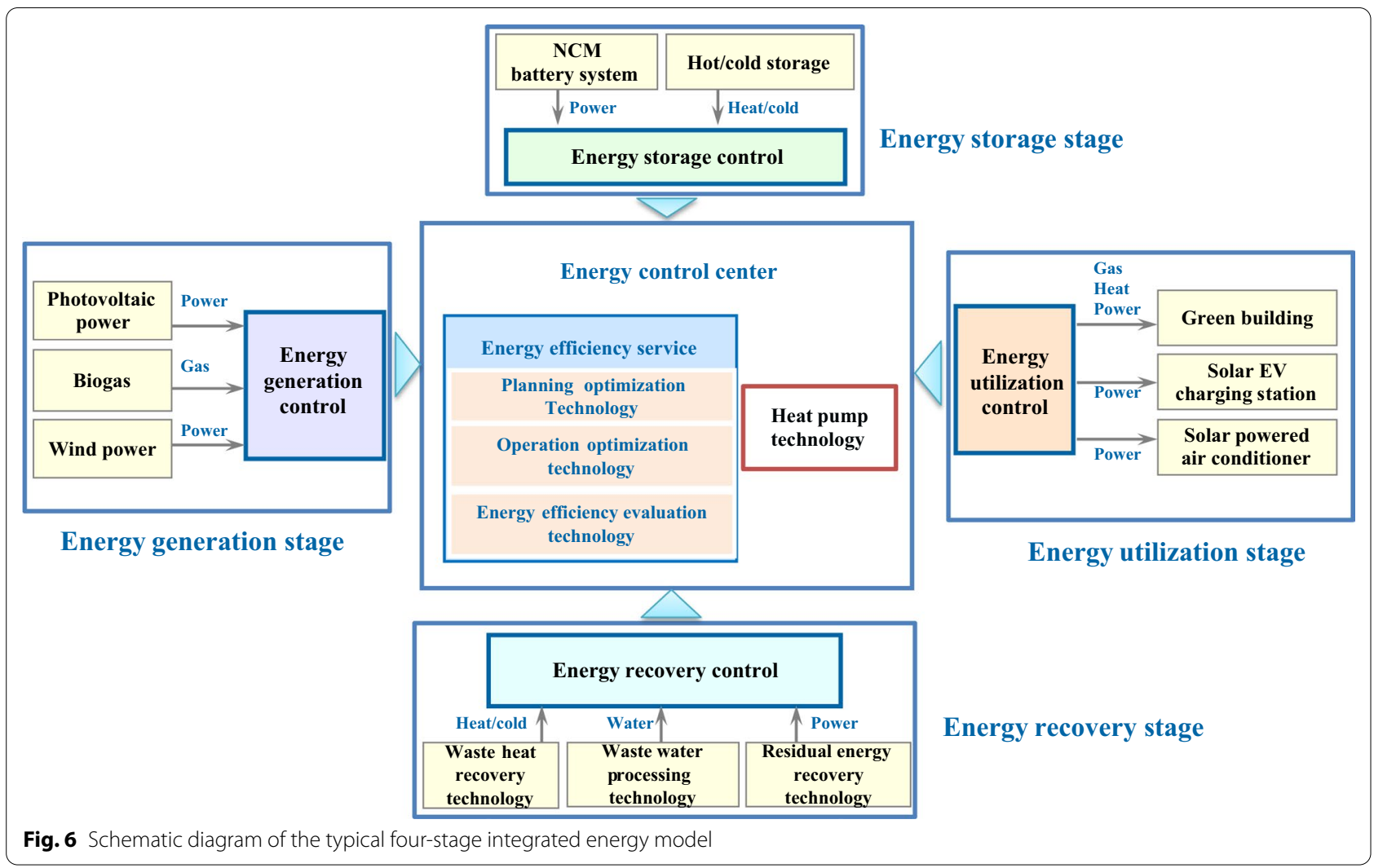

development of a city, especially for a new district [15]. Nevertheless, in past practice, energy planning of a planned district was not incorporated into the statutory city planning system, primarily because there were no clear standards and specifications for these plans [16]. On the other hand, energy-optimized urban planning has become a gradually accepted concept towards green economy and clean energy production [17]. The energy system integrated in the city territory is a complex infrastructure that has both technical and non-technical elements with multiple dynamic interactions. Thus, the sustainable long-range planning of such a system that involves different planning participants is very challenging and full of uncertainties [18]. From the view of the existing problems in the coordinated development of city planning and energy planning, it is obvious that the present mode of city and energy planning should be converted into a new integrated mode [19-22].

The presented case study should illustrate how the methodology proposed in this paper is used for energy planning. The typical DEN case system is located at the Sino-German Eco-Park in the Qingdao City, Shandong province. Figure 7 illustrates the sketch map of the SinoGerman Eco-Park planning. The planning of this project was carried out according to the methodology described

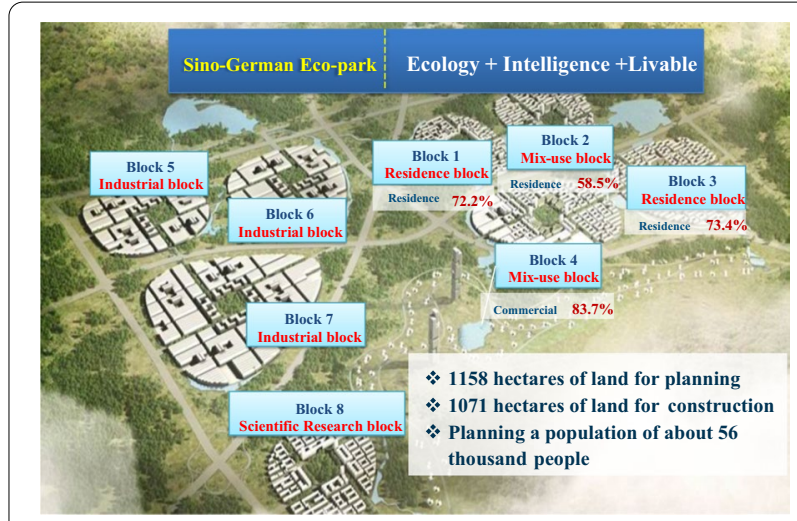

Fig. 7 Sketch map of the Sino-German Eco-Park planning

1. According to the energy consumption characteristics of the end users, the energy demand was reduced by an energy-saving technology, such as window ventilation, tunnel ventilation, external wall insulation, energy-saving control, etc.

2. To reduce the consumption of fossil energy, local energy and all resources were fully exploited, with a high priority to use natural and peripheral waste heat resources, in the above section and applied the following principles. 
3. With one regional energy station and six distributed energy stations connected by a "micro-energy network", a balanced utilization of renewable and fossil energy was achieved, which could improve the overall energy-efficiency and the reliability of the EcoPark.

4. With energy supervision, scheduling and transaction services, the interaction between energy supply and utilization in the Eco-Park could be realized, ensuring an optimization and matching of the whole energy network system operated with high efficiency.

\section{Structure design of the four-stage loop}

A detailed plan presented in Fig. 8 was established for the DEN system of the Sino-German Eco-Park. One large regional energy station and three small commercial distributed energy stations were set up in the residential and commercial areas, whereas three small industrial distributed energy stations were set up in the industrial zone.

CCHP, photovoltaic solar, photovoltaic thermal solar energy as well as wind energy, biogas, geothermal energy, water source heat, industrial residual energy and other new types of energy were integrated to meet more than $80 \%$ of the energy demand of the Eco-Park. The storage systems of electricity, gas and heat were set up in each distributed energy station. The regional energy stations were connected with the industrial and commercial distributed energy stations through a main steam pipeline, and the industrial and commercial sub-stations were connected with end users through the micro-energy network in each block. A variety of energy sources, such as cold, heat, electricity, steam and gas, were provided to end users. Multi-energy complementary systems and peak shaving of various energy sources among the distributed energy stations were realized by the interconnectivity of the DEN system.

The entire DEN planning process is divided into the following steps. Firstly, it predicts the energy demand of end users and the energy quantity obtained from the environment and optimizes the different energy load curves with regard to time and space, and arranges an optimal design of the multi-energy supply system based upon optimized energy loads, and last but not least, it determines the scale of the distributed energy stations. Secondly, according to the energy demand of the Eco-City, it also determines the number and position of the distributed energy stations, designs the connection scheme and the complementary peak regulation scheme between the distributed energy stations, and sets up the basic-energy network of the Sino-German Eco-Park. Upon the utilization of the Sensor-Control Network and the Intelligent Network, a coupling network for energy and information is created. With control, optimization, scheduling and transaction of the energy system, the planning of the DEN system of the Sino-German Eco-Park was finished. Finally, a

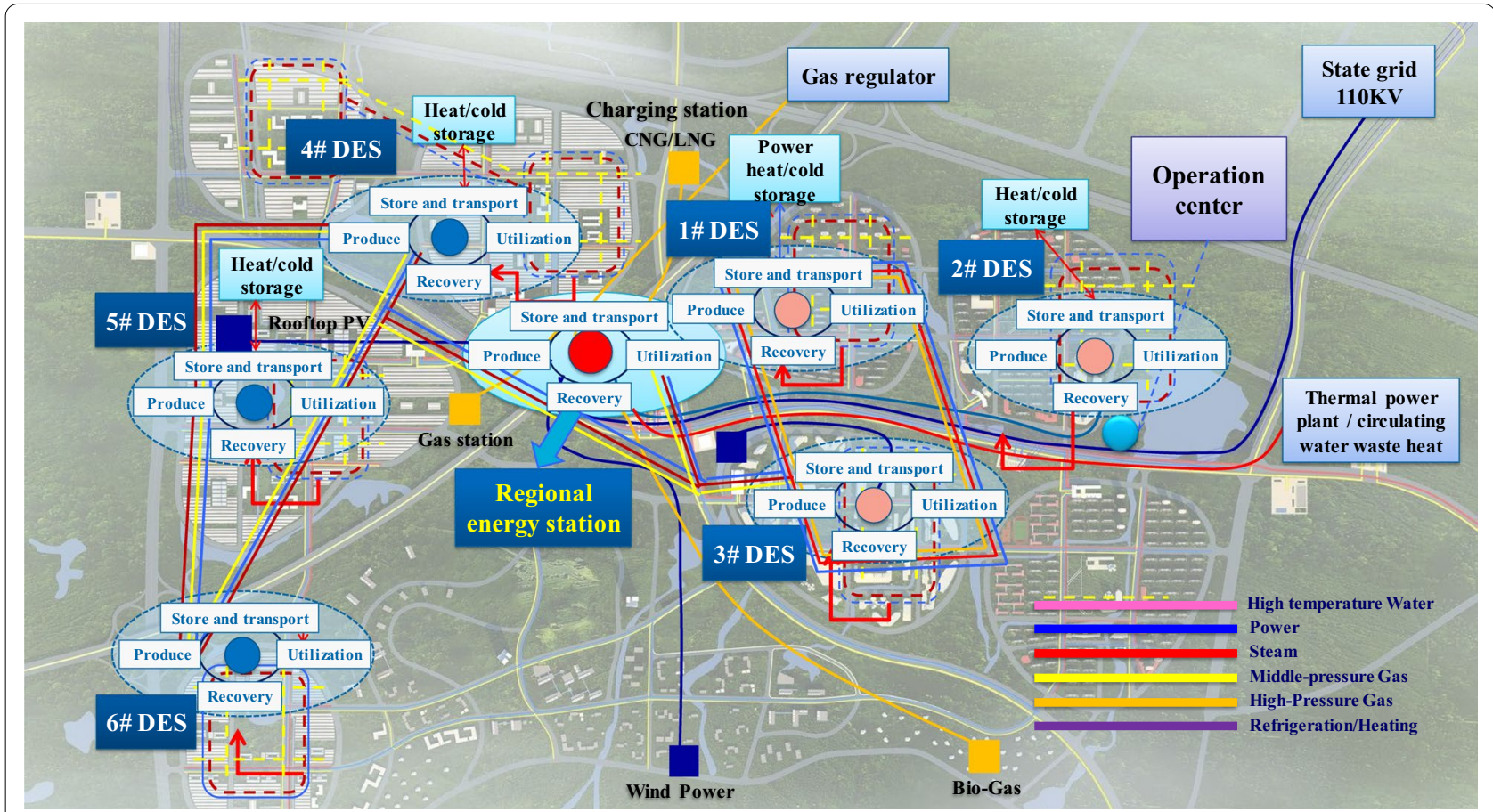

Fig. 8 Four-stage schematic diagram integrated in the Sino-German Eco-Park 
technical and economic analysis of the DEN system and an evaluation of the effect of the comprehensive planning in regard to energy efficiency, environment and economy should be performed.

\section{Analysis of resource conditions}

Qingdao is located at the north latitude of $36^{\circ} 09^{\prime}$ and the east longitude of $120^{\circ} 25^{\prime}$, belonging to the temperate zone of marine climate, where the annual average temperature is $12.5^{\circ} \mathrm{C}$ with an average temperature in the hottest month (August) of $25.3^{\circ} \mathrm{C}$ and an average temperature in cold months (January) of $-0.9^{\circ} \mathrm{C}$. According to the climate division of buildings, the heating period in Qingdao amounted to 141 days. A thorough analysis of various available resources should be described as follows.

1. Solar energy: the ecological park has good solar energy utilization conditions. Qingdao has a total solar radiation of $5040 \mathrm{MJ} / \mathrm{m}^{2}$, with an annual average sunshine time of $2550 \mathrm{~h}$, and the percentage of sunshine amounts to 58\%. Thus, it belongs to the third type of solar energy distribution in China.

2. Wind energy: the wind resources found in the EcoPark are characterized

a. By an annual average wind speed in Qingdao that amounted to $5.3 \mathrm{~m} / \mathrm{s}$ with a dominant wind direction of southeast and a maximum wind speed of $38 \mathrm{~m} / \mathrm{s}$

b. By an effective wind energy density of up to $240.3 \mathrm{~W} / \mathrm{m}^{2}$, and an annual average time for effective wind energy amounting to $6485 \mathrm{~h}$.

3. At present, a $50 \mathrm{MW}$ wind power plant is under construction on the southern side of the ecological park.

4. Shallow geothermal energy: the ecological composition is mainly sandstone, with weathered granite under $0-30 \mathrm{~m}$ and sandstone under $30-120 \mathrm{~m}$. The comprehensive thermal conductivity of the region is $1.464 \mathrm{~W} /\left(\mathrm{m} \cdot{ }^{\circ} \mathrm{C}\right)$, and the average value is $1.847 \times 10^{6} \mathrm{~J} /\left(\mathrm{m}^{3} \cdot{ }^{\circ} \mathrm{C}\right)$, which is more suitable for the application of a ground source heat pump. However, the cost of well drilling is very high. Thus, it is necessary to balance the relationship between renewable energy utilization and economic costs.

5. Water source heat energy: there are many reservoirs near the ecological park. In summer, the temperature of the lake water increases by $1{ }^{\circ} \mathrm{C}$ per week, which provides a refrigeration capacity of 5-10 MW. In winter, the temperature of the lake water decreases by $2{ }^{\circ} \mathrm{C}$ per week, which provides a heating capacity of 25-50 MW. The influence of a water temperature change on the ecological environment should be taken into account when the water source heat pump is designed.

6. Municipal engineering: a $200 \times 10^{3}$ ton/day sewage treatment plant, one waterworks with a supply capacity of $100 \times 10^{3} \mathrm{~m}^{3} / \mathrm{d}$, a high-medium pressure regulator station for natural gas with an supply capacity of about $730 \times 10^{6} \mathrm{~m}^{3} /$ year, two $660 \mathrm{MW}$ plus two $225 \mathrm{MW}$ power generation units for the power plant and two $750 \mathrm{MW}$ sub-stations are part of the project.

After analyzing the local conditions with the available energy resources, the next step should be to forecast and optimize the energy load demand of each block. This is the key step in the entire process, because it directly determines the technical and economic indicators of the project, which provides the basis for its investment decision.

\section{Energy load forecasting and optimization}

The main energy consumption of the Eco-Park divided into multiple demand types, such as cold, heat, electricity, natural gas and steam is listed in Table 1 . The electric, gas, cold/heat and steam loads of public buildings and houses were calculated by the DeST, which is a software platform for building environment and HVAC system simulations. The model is shown in Fig. 9.

The electric, gas, cold/heat and steam loads of other buildings were calculated by the design index that is provided by the Chinese national standard. The characteristic curves of the energy consumption of each block based

Table 1 Types of the load of energy supply

\begin{tabular}{|c|c|c|c|c|c|c|c|c|c|}
\hline \multirow[t]{2}{*}{ Classification } & \multirow[t]{2}{*}{ Cold/heat } & \multicolumn{3}{|c|}{ Electric power } & \multicolumn{3}{|c|}{ Natural gas } & \multirow[t]{2}{*}{ Steam } & \multirow{2}{*}{$\begin{array}{l}\text { Domestic } \\
\text { hot water }\end{array}$} \\
\hline & & Living office & Industry & Traffic & Domestic & Industry & Traffic & & \\
\hline Residence buildings & $\sqrt{ }$ & $\sqrt{ }$ & - & - & $\sqrt{ }$ & - & - & - & $\sqrt{ }$ \\
\hline Public buildings & $\sqrt{ }$ & $\sqrt{ }$ & - & - & $\sqrt{ }$ & - & - & - & $\sqrt{ }$ \\
\hline Industry & $\sqrt{ }$ & $\sqrt{ }$ & $\sqrt{ }$ & - & - & $\sqrt{ }$ & - & $\sqrt{ }$ & - \\
\hline Transportation & - & - & - & $\sqrt{ }$ & - & - & $\sqrt{ }$ & - & - \\
\hline
\end{tabular}




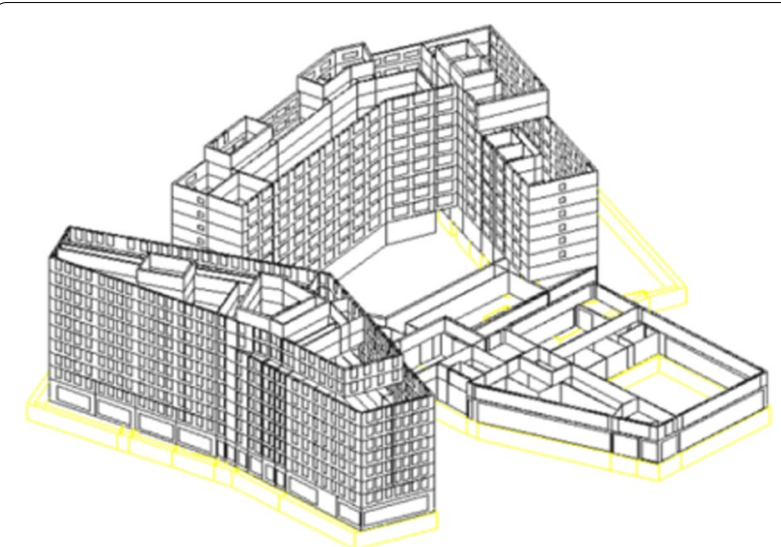

Fig. 9 DeST model for the German Center in Block 2

on $24 \mathrm{~h}$ are calculated, and the consumption scale of electric, gas, cold/heat and steam load after optimization of each block were obtained. According to the typical daily energy load characteristics of each block, combined with the regional peak/valley electricity price, the peak load of the energy can be cut off by using an energy storage system to achieve the Time-Domain Analysis and Optimization, which could reduce the loading scale of the energy supply system. The load of energy in each block was calculated as listed in Table 2. Block 1 and 3 are mainly residence buildings, Block 2 and 4 are mainly a combination of residence buildings and public buildings, and the other blocks are mainly industrial and public buildings.

It seems that the calculated energy load based on the design index of the cold and heat load of the classified buildings is high and there exists a sufficient space to reduce energy through optimization. It was found that the load between different blocks has a simultaneous peak load shifting, which leads to a difference in the operating rate of the equipment. In addition, the allocation of the energy between the distributed energy stations could be realized by a DEN system that connected the adjacent stations, which allows the energy supply for the distribution network to be calculated.

When taking Block 1 as an example, as shown in Fig. 10, in order to optimize the heat load curve based on peak load shifting, the left side (1) (for the valley period of 22-7) carried out the energy storage, and the right side (2) and (3) (peak) released the stored energy. The blue curve shows the case without optimization, and the red curve shows the case with optimization by using the storage systems. After installing the energy storage in the distributed energy station, the installed capacity of the other energy equipment could be reduced.

As shown in Fig. 11, Block 1 and Block 4 are adjacent blocks, with Block 1 mainly being a residence block and Block 4 mainly being a business block. Due to the difference in the energy behavior and characteristics, at AM $7-8$, about $10 \mathrm{MWh}$ energy is allocated from Block 4 to Block 1, while at AM 10-11, about the $2 \mathrm{MWh}$ energy is allocated from Block 1 to Block 4. By doing so, it not only

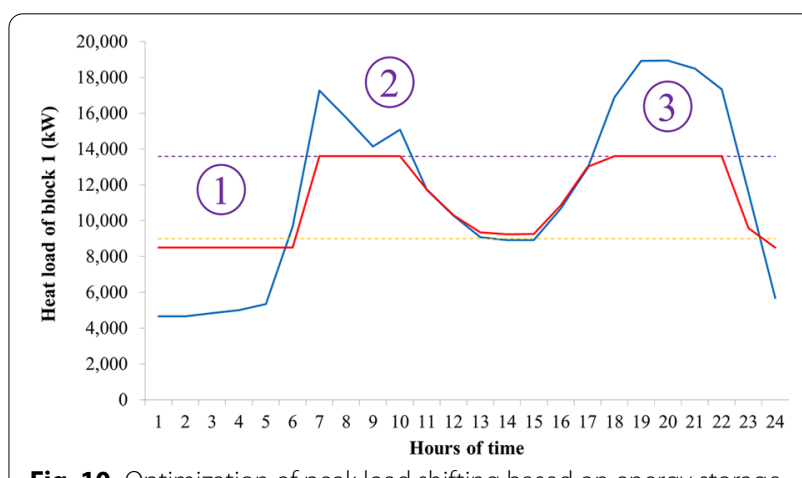

Fig. 10 Optimization of peak load shifting based on energy storage

Table 2 Summary of the energy utilization load

\begin{tabular}{lllllllll}
\hline $\begin{array}{l}\text { Block } \\
\text { Building } \\
\text { area }\left(\times 10^{4}\right. \\
\left.\mathrm{m}^{2}\right)\end{array}$ & Hot load (kW) & Cold load (kW) & Electric load (kW) & $\begin{array}{l}\text { Accumulated } \\
\text { cooling load } \\
\text { (MWh/a) }\end{array}$ & $\begin{array}{l}\text { Accumulated } \\
\text { hot load } \\
\text { (MWh/a) }\end{array}$ & $\begin{array}{l}\text { Accumulated } \\
\text { electric load } \\
\text { (MWh/a) }\end{array}$ & $\begin{array}{l}\text { Accumulated } \\
\text { hot-water } \\
\text { load(MWh/a) }\end{array}$ \\
\hline 1 & 64.39 & 18,947 & 10,133 & 16,964 & 5677 & 23,421 & 36,598 & 14,704 \\
2 & 72.87 & 21,387 & 26,154 & 18,106 & 14,826 & 27,011 & 44,542 & 13,815 \\
3 & 60.64 & 18,298 & 9278 & 16,472 & 5429 & 22,894 & 34,770 & 12,387 \\
4 & 114.84 & 45,791 & 79,037 & 27,969 & 46,877 & 46,174 & 81,640 & 13,625 \\
5 & 42.18 & 10,886 & 14,514 & 16,436 & 8002 & 7782 & 35,975 & 381 \\
6 & 81.09 & 18,324 & 24,069 & 34,931 & 13,750 & 13,699 & 71,798 & 308 \\
7 & 93.81 & 22,984 & 30,646 & 37,969 & 16,896 & 16,431 & 81,069 & 706 \\
8 & 39.71 & 9158 & 12,210 & 16,732 & 6732 & 6546 & 34,812 & 233 \\
9 & 188.24 & 97,651 & 129,338 & 41,184 & 71,407 & 78,263 & 99,759 & 8503 \\
Total & 757.77 & 263,425 & 335,378 & 226,764 & 189,595 & 242,221 & 520,964 & 64,662 \\
\hline
\end{tabular}




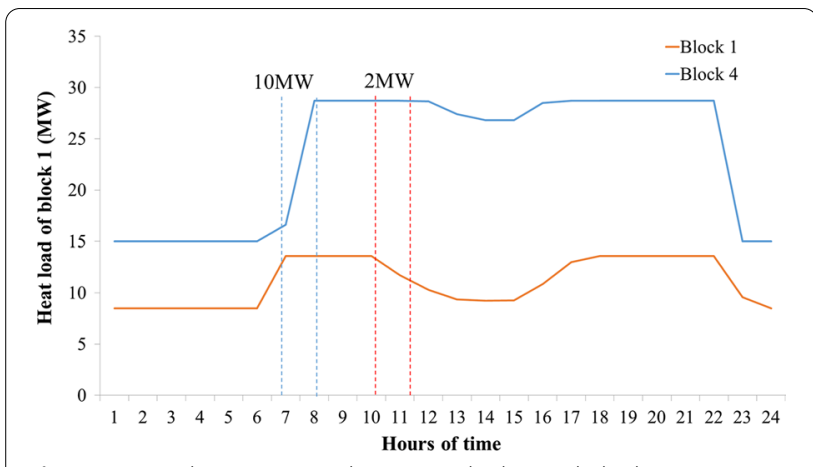

Fig. 11 Spatial optimization between Block 1 and Block 4

reduces the number of standby equipment of the distributed energy stations in the DEN system, but also provides a smooth operation for the DEN system in the following stage. The reduced capacity with optimization refers to Table 3. After calculating the load of the whole Eco-Park, the next step aims at supplying the energy sources of cold, heat, electricity and gas for the ecological park and putting forward various regional energy supply schemes.

\section{Energy supply planning and distributed energy station design}

Technical options would affect the investment decision of the whole project and the cost of the operation in the future. Thus it is important to choose a suitable solution to meet the energy demands of the entire Eco-Park by paying attention to the environmental and social effects, such as total energy consumption, energy saving, $\mathrm{CO}_{2}$ emission reduction and renewable energy utilization. As listed in Table 4, we would present five plans with suitable technical solutions and carry out a comprehensive analysis by comparison, in order to find the best solution.

In Solution 1, the heat load is provided by the city's central heating station in winter, and in summer, electric refrigerators are used to meet the demands for the cold loads. The investment and energy loss of the pipelines was high. Domestic hot water was provided by gas boilers. Solution 2 uses gas and electricity as the main energy sources, thus its operating cost is relatively high. In Solution 3, gas is used as the main energy source, which consumes a lot of gas and needs a high operating cost. In contrast, Solution 4 is better as it uses CCHP, but

Table 3 Reduced capacity after optimization

\begin{tabular}{lllllllll}
\hline Block & 1 & 2 & 3 & 4 & 5 & 6 & 7 & 8 \\
\hline Optimal design of cold load (kW) & 9300 & 23,000 & 7500 & 70,000 & 11,500 & 20,000 & 26,500 & 10,000 \\
Percentage reduction in installed capacity (\%) & 8.2 & 12.1 & 19.2 & 11.4 & 20.8 & 16.9 & 13.5 & 18.1 \\
Optimal design of heat load(kW) & 18,000 & 17,700 & 14,600 & 28,700 & 6000 & 10,000 & 13,000 & 5000 \\
Percentage reduction in installed capacity (\%) & 5 & 17.2 & 20.2 & 37.3 & 44.9 & 45.4 & 43.4 & 45.4 \\
\hline
\end{tabular}

Table 4 Comparison between the five suitable technical solution plans

\begin{tabular}{|c|c|c|c|c|c|c|}
\hline & & Solution 1 & Solution 2 & Solution 3 & Solution 4 & Solution 5 \\
\hline \multicolumn{2}{|c|}{ Total energy consumption (Tce) } & 295,146 & 271,374 & 272,755 & 282,639 & 149,380 \\
\hline \multicolumn{2}{|c|}{$\mathrm{CO}_{2}$ emission reduction rate, $\%$} & - & 13.8 & 14.7 & 12.7 & 64.6 \\
\hline \multicolumn{2}{|c|}{ Clean energy utilization rate, \% } & 6.12 & 27.1 & 30.2 & 32.4 & 80.4 \\
\hline \multicolumn{2}{|c|}{ Renewable energy utilization rate, \% } & 0 & 0 & 0 & 0 & 20.6 \\
\hline \multicolumn{2}{|c|}{ Total investment cost (100 × 10 $0^{6}$ yuan) } & 15.0 & 15.4 & 16.8 & 18.3 & 19.2 \\
\hline \multirow[t]{2}{*}{ Annual operating cost } & Fuel cost, $\times 10^{8}$ yuan & 2.53 & 2.31 & 2.39 & $\begin{array}{l}1.30 \text { (offset power } \\
\text { generation } \\
\text { income) }\end{array}$ & $\begin{array}{l}0.4 \text { (offset power } \\
\text { and steam } \\
\text { revenue) }\end{array}$ \\
\hline & Maintenance cost, $\times 10^{4}$ yuan & 600 & 500 & 300 & 3000 & 6500 \\
\hline \multicolumn{2}{|c|}{ Static investment recovery period, year } & 9 & 5 & 5 & 8 & 11 \\
\hline
\end{tabular}

Tce means ton of standard coal equivalent, which is a unit of the Chinese standard unit of energy measurement. It is used for the macro statistics of the energy consumption from various types of energy sources such as coal, oil, natural gas, electricity, etc.

Solution 1: urban central heating (urban heating) + municipal power (cooling, electricity) + gas pipe network (natural gas)

Solution 2: electric refrigerator (cooling) + gas boiler (heating) + municipal power (electricity) + gas pipe network (natural gas)

Solution 3: LiBr direct combustion unit (cooling, heating) + municipal power (electricity) + gas pipe network (natural gas)

Solution 4: CCHP (cooling, heating, electricity) + gas boiler (heating peak shaving) + water cooling unit (cooling peak shaving) + municipal power (electricity) + gas pipe network (natural gas)

Solution 5: multiple distributed energy stations (cooling, heating, electricity) + municipal power (supplementary power supply) + external waste heat source (partial ratio heating) + micro-energy network 
could not achieve the energy allocation between different blocks. Therefore, considering the local energy resource conditions, energy saving, environmental, economic and social benefits, Solution 5 was selected as the energy system design for the Eco-Park. As shown in Fig. 12, it includes an energy allocation system to meet the energy supply of the eight blocks. According to the calculation and optimization of the energy demand, the energy supply of the entire DEN system reached $276 \mathrm{MW}$ for heating, 352.2 MW for cold, $30 \mathrm{t} / \mathrm{h}$ for industrial steam, and $76 \mathrm{MW}$ for power supply, which would meet the entire energy demand for the Eco-Park.

The regional energy station based upon a natural gas and steam-combined cycle is the key component of the system, as shown in Fig. 13. After burning gas through the gas turbine, both the electric power and a certain amount of high-temperature flue gas were produced. The high-pressure and high-temperature steam is produced when high-temperature flue gas was put into the waste heat boiler, and steam of high temperature and high pressure entered the steam turbine to perform the power generation. Two types of steam turbines are used, i.e., the backpressure steam turbine and extraction-condensing turbine, where the backpressure steam turbine was used to produce a stable steam for industrial users in the industrial area. Some steam was also extracted from the extraction-condensing turbine for the refrigeration and heating of the system during operation. The high-temperature flue gas discharged from the heat recovery steam generators (HRSG) was used for living hot water.

The regional energy station was adopted to the model of a semi-underground structure with one upper and one lower floor with an area of $6000 \mathrm{~m}^{2}$ and a total construction area of about $10,000 \mathrm{~m}^{2}$. It is responsible for energy dispatching inside and outside the park, for supplying industrial production with steam and for adjusting the energy supply balance between the industrial area and the commercial area.

The structure diagram of the 1\# DES is shown in Fig. 14. The $1 \#$ DES is mainly composed of CCHP, an electrical refrigerator, a boiler, a ground source heat pump and an energy storage system. The station was built in the underground area with a total planning area of $4000 \mathrm{~m}^{2}$. It mainly served Block 1 and part of Block 4, including residential, commercial and office buildings. The total energy supply area is $6.44 \times 10^{5} \mathrm{~m}^{2}$. After the completion of the 1 \# distributed energy station, it is expected to meet the demand of $3 \mathrm{MW}$ power load, 10.6 MW cold load, and 19.6 MW heat load.

The scale of energy supply of each distributed energy station listed in Table 5 is connected with the designed scheme of the 1\# DES. Block 9 of the Eco-Park, located at the northern side of the mountain, is very different from the other blocks. Therefore, the energy supply of Block 9 should meet the cold and heat demands in this area by

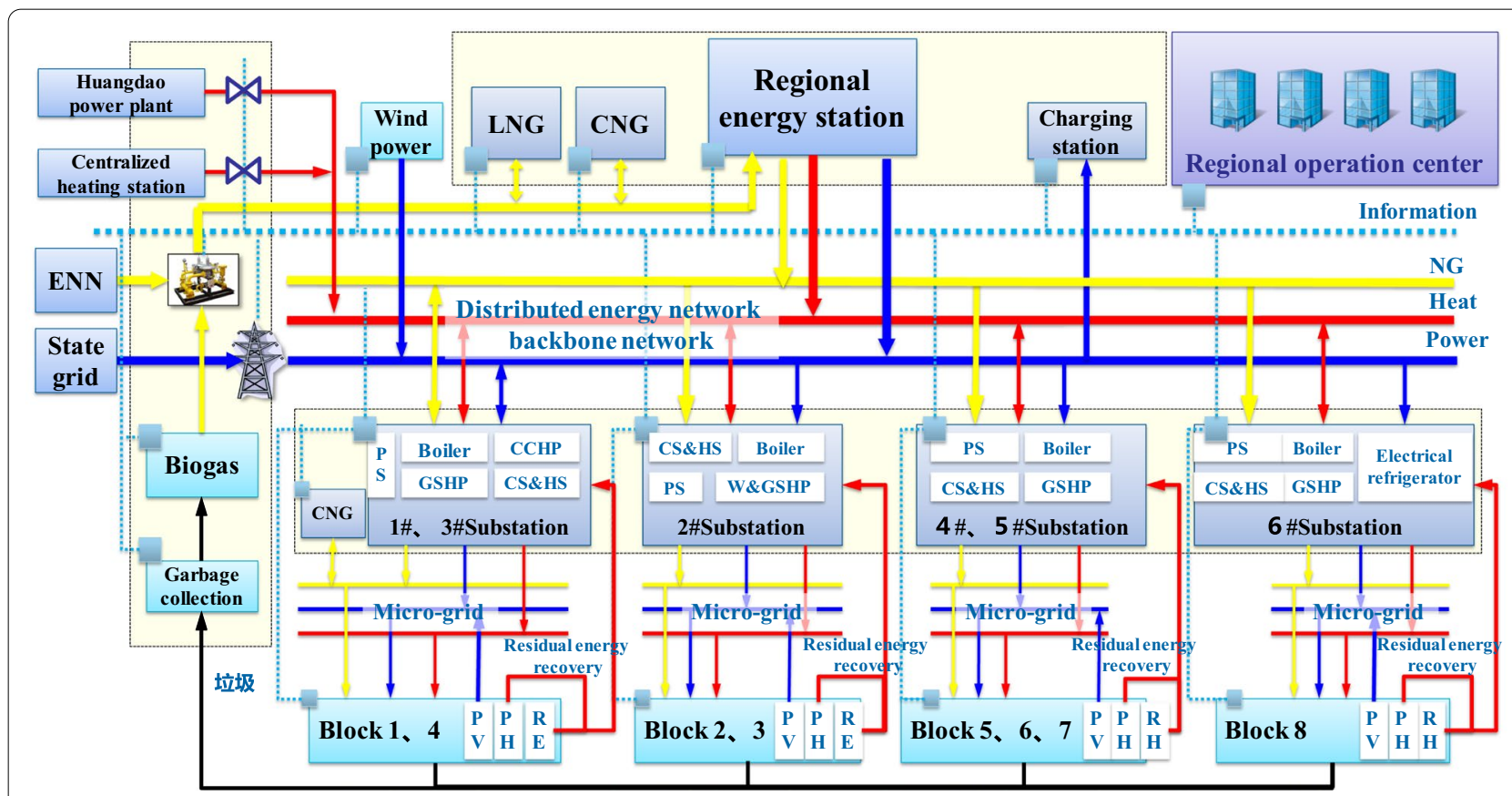

Fig. 12 Structure diagram of the distributed energy network system in the Sino-German Eco-Park 

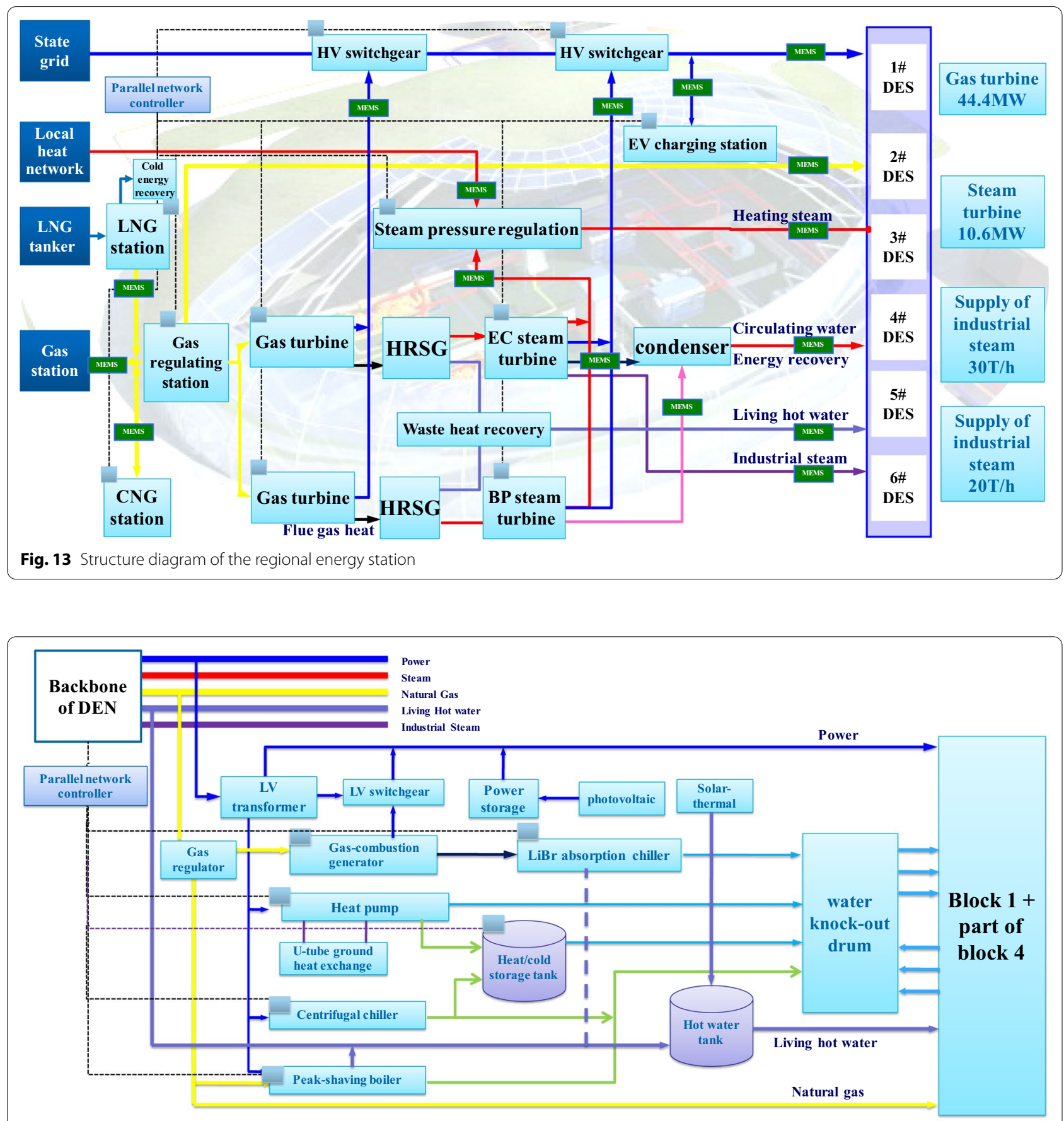

Fig. 14 Structure diagram of the 1\# distributed energy station

using its own distributed energy station, mainly with a direct-fired absorption chiller and air source heat pump.

Next, for all distributed energy stations with optimization of energy load, time and space load was determined (using Load Superposition Technology), and the overall investment amount of the project could be reduced, but the distributed energy sub-station could still not meet the load demand of the region directly. A proper DEN control system must be designed to meet the energy demand of the Eco-Park, while ensuring the social, economic and environmental effects for SinoGerman Eco-Park. 
Table 5 The scale amount of energy supply for all distributed energy stations

\begin{tabular}{llllll}
\hline DES no. & $\begin{array}{l}\text { Total energy } \\
\text { supply area, } \\
\mathrm{m}^{2}\end{array}$ & Block no. & $\begin{array}{l}\text { Power } \\
\text { load, } \\
\text { MW }\end{array}$ & $\begin{array}{l}\text { Cold load, } \\
\text { MW }\end{array}$ & $\begin{array}{l}\text { Heat load, } \\
\text { MW }\end{array}$ \\
\hline $1 \#$ & $6.44 \times 10^{5}$ & 1,4 & 3 & 10.6 & 19.6 \\
$2 \#$ & $1.335 \times 10^{6}$ & 2,3 & 5 & 37.3 & 19.8 \\
$3 \#$ & $1.148 \times 10^{6}$ & 1,4 & 5 & 83 & 48.1 \\
$4 \#$ & $1.233 \times 10^{6}$ & 5,6 & 0 & 40.5 & 30.7 \\
$5 \#$ & $9.38 \times 10^{5}$ & 7 & 0 & 32.2 & 24.1 \\
$6 \#$ & $3.97 \times 10^{5}$ & 8 & 0 & 12.8 & 9.6 \\
\hline
\end{tabular}

\section{Design of a distributed energy network system}

The architecture of the DEN system in the Sino-German Eco-Park is illustrated in Fig. 15. It is divided into three layers at the network level, i.e., the basic-energy network, the sensor control network and the Smart information network.

The sketch map of the DEN system in Sino-German Eco-Park is depicted in Fig. 16. The 1\#, 2\# and 3\# substations of the commercial area and the $4 \#, 5 \#$ and $6 \#$ sub-stations of the industrial area are interconnected by a heat pipeline network, a natural gas pipeline network and a power grid in each area, respectively. By controlling the amount of high-pressure steam, natural gas and high voltage electricity that is transported through the regional energy station of $1 \#, 2 \#, 3 \#, 4 \#, 5 \#$ and $6 \#$ substation, the allocation of the energy between the industrial and commercial area is realized.

After completion of all energy stations, except Block 9 that uses separate energy stations, the regional energy station and all sub-stations were connected with the main DEN system, which could not only exchange energy between the sub-stations but also allocate different types of energy between the industrial and commercial areas. The sensor control network consisted of various control nodes, such as the distributed network controller, the real-time controller of the field equipment, the end user executor, etc. The sensor control network mainly acquired data, controlled all levels of equipment in the park and executed instructions sent by the smart information network. The main part of the sensor control network in the Eco-Park integrated the distributed energy backbone network. By utilizing a facility construction, it will greatly reduce the total construction cost.

The whole sensor control network is mainly composed of network controller, intelligent energy-efficiency platform, energy-efficiency controller and an operation center. It conducted the measurement for the energy used by each building, including electric, water, heat and gas, and also controlled all aspects of the energy utilization system, such as switching and valves. The remote control of the energy by end users in various areas of the buildings is used to measure the cost, and all the data could be uploaded to the operation center.

The DEN system of the Sino-German Eco-Park is an intelligent and high-efficient energy network. It is necessary to establish a smart information network to realize the intelligent and ecological operation of the DEN system of the Eco-Park. Based upon a cloud-computing network, it supported the efficient operation of the entire energy system through energy-efficiency control, system optimization, overall scheduling and whole network

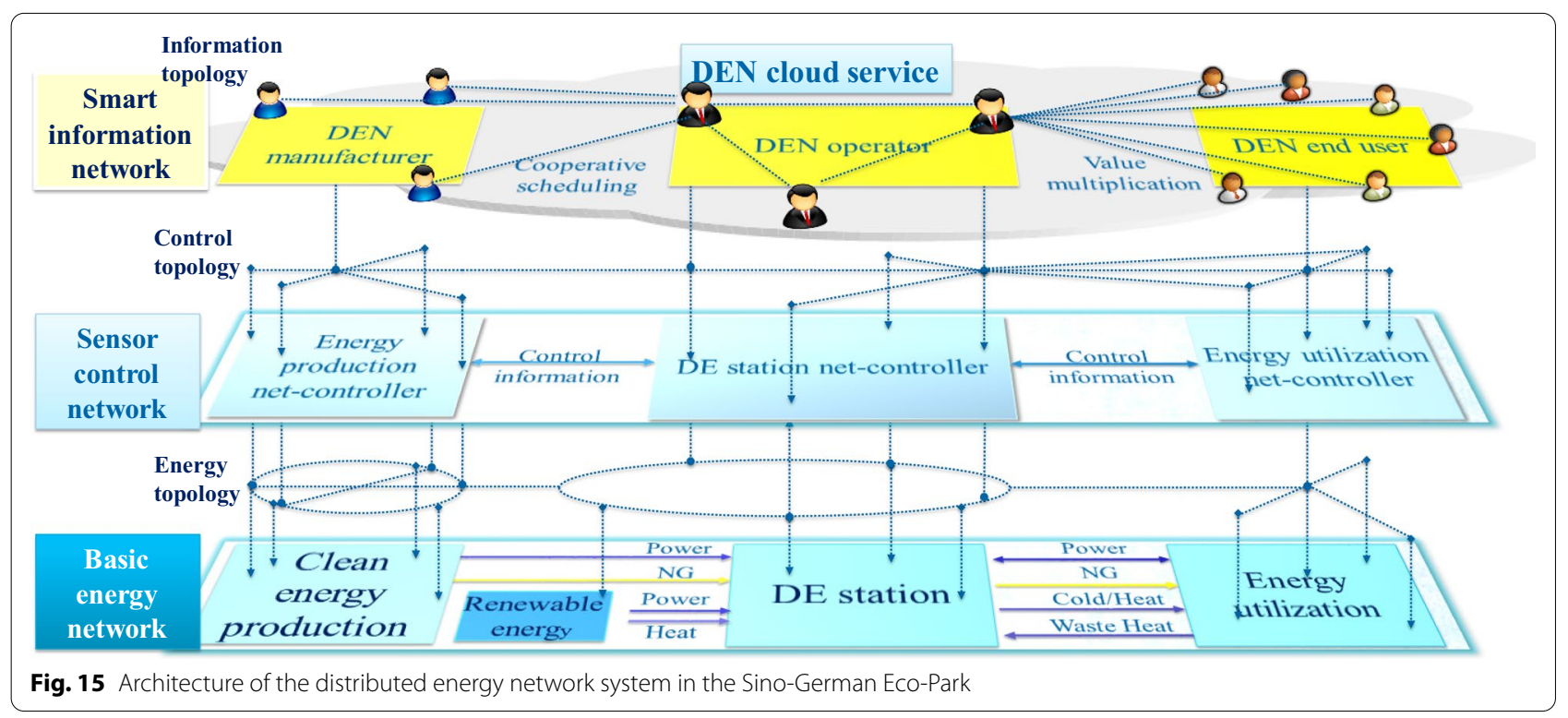




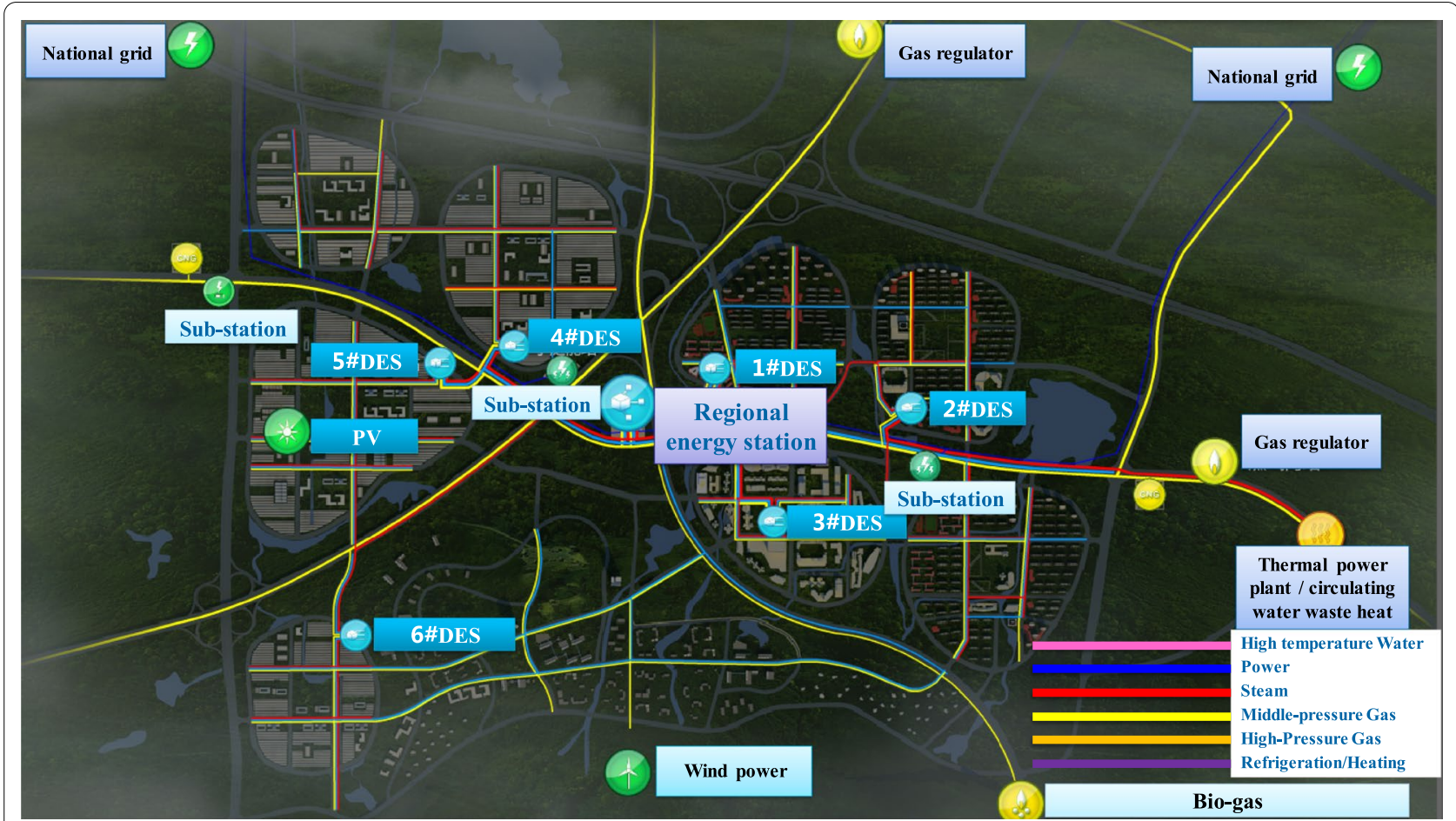

Fig. 16 Sketch map of the distributed energy network in the Sino-German Eco-Park

monitoring, to provide integrated energy services for industrial and commercial enterprises, residents and other energy end users in the park. The technical architecture diagram of the smart information network system in the Sino-German Eco-Park is shown in Fig. 17. The smart information network not only realized the energy management and scheduling and optimization of the entire energy network system, but also provided energy services and transactions for end users. It is divided into three layers, i.e., the physical layer, system layer and service layer. In the physical layer, all the data were obtained from the different sensors and controllers of the entire DEN system of the Eco-Park, which uploaded them to the data service cluster. After virtualization of the data, it distributed them to different functional subsystems at the system level, in order to realize efficiency control,

\begin{tabular}{|c|c|c|c|c|}
\hline $\begin{array}{l}\text { Service } \\
\text { layer }\end{array}$ & $\begin{array}{l}\text { Energy schedule } \\
\text { (supply and } \\
\text { demand matching, } \\
\text { overall scheduling) }\end{array}$ & $\begin{array}{l}\text { Energy trading } \\
\text { (residual energy } \\
\text { utilizing, energy } \\
\text { transaction) }\end{array}$ & $\begin{array}{l}\text { Public service } \\
\text { (government, } \\
\text { enterprise, } \\
\text { resident) }\end{array}$ & Energy cloud services \\
\hline \multirow{2}{*}{$\begin{array}{l}\text { System } \\
\text { layer }\end{array}$} & $\begin{array}{l}\text { Energy efficiency } \\
\text { control } \\
\text { (service level, system } \\
\text { level) }\end{array}$ & $\begin{array}{l}\text { Energy efficiency } \\
\text { optimization } \\
\text { (prediction, } \\
\text { optimization) } \\
\end{array}$ & $\begin{array}{l}\text { Energy supervision } \\
\text { (collection, } \\
\text { monitoring, early } \\
\text { warning) }\end{array}$ & \multirow{2}{*}{$\begin{array}{l}\text { Diagnosis and } \\
\text { optimization of energy } \\
\text { stream }\end{array}$} \\
\hline & \multicolumn{3}{|c|}{$\begin{array}{l}\text { Basic support subsystem (security authentication, user } \\
\text { permissions, data management, network monitoring, etc.) }\end{array}$} & \\
\hline \multirow{2}{*}{$\begin{array}{l}\text { Physical } \\
\text { layer }\end{array}$} & \multicolumn{3}{|c|}{ Energy cloud server cluster } & Big data \\
\hline & \multicolumn{3}{|c|}{$\begin{array}{c}\text { Intelligent meter of } \\
\text { Energy transfer network } \\
\text { Integrated energy network infrastructure }\end{array}$} & $\begin{array}{l}\text { (Massive information } \\
\text { processing ) }\end{array}$ \\
\hline
\end{tabular}


optimization and supervision of energy. The service layer is the core to realizing the intelligent interaction of the DEN system, which is composed of an energy scheduling subsystem, an energy transaction subsystem and a public service subsystem. The entire system is built on both the private and public cloud by using big data technology.

\section{Technical and economic analysis}

Based on the analysis of the energy load and the integrated DEN system design, combined with Sino-German Eco-Park planning, the situation of energy conservation and $\mathrm{CO}_{2}$ emission reduction of the Eco-Park was analyzed in detail for determining the energy and environmental indicators necessary to meet the high criteria of the world of the future. The technical indicators of the Sino-German Eco-Park are listed in Table 6. It is obvious that all the indexes have reached high criteria in China. The DEN system of the Eco-Park has vigorously promoted the integration and utilization of energy, resources and information. It is evident that the DEN system based on the integration of natural gas and renewable energy with a smart energy network would be suitable for in the development and operation of the Eco-Park in the future.

\section{Current status and existing problems}

From 2012 to 2019, this project underwent more than 5 years of construction. The aerial view of the $1 \#$ and 2\# DES area is given in Fig. 18. The Sino-German EcoPark project is the first exploration of a DEN system in China. Therefore, there were many problems in the past due to long construction times and there could be potentially unknown factors affecting future operations. The encountered problems offer us all a valuable experience, and a timely summarization would provide lessons as reference for the development of future similar projects.

The speed of construction was mainly affected by factors such as the attractiveness of the investment. For residential Block 1, the occupancy rate of the residents did not reach the expected number, leading to an energy consumption that did not reach the planning goals. Thus

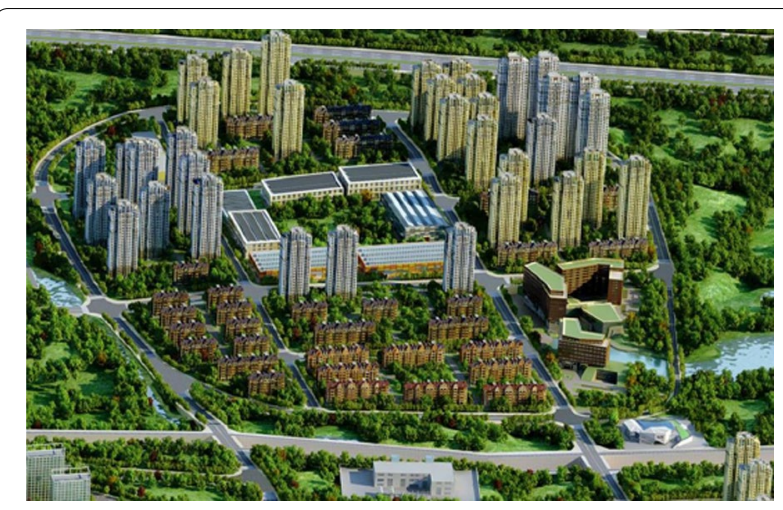

Fig. 18 An aerial view of the 1\# and 2\# distribute energy station area

the scale of the distributed energy station and the infrastructure and pipeline network is larger compared to its practical needs, and part of the investment was wasted.

Because the occupancy rate for part of the blocks is not up to the expected value, the energy consumption is insufficient and the energy loss in heat transfer among the stations is large. Taking the case of Station $1 \#$ and $2 \#$ as examples, there is about a $3-\mathrm{km}$ distance between the two stations. Since the residential users in Block 1 used heat energy less than the designed amount, and the capacity of the commercial users in Block 2 was also insufficient, a smaller flow rate of hot water and a larger temperature difference for transferring the heat was achieved. The temperature of the hot water from station 1 \# to station $2 \#$ decreases from 130 to $80^{\circ} \mathrm{C}$, and the heat energy loss amounted to more than $20 \%$. However, based on the original design of the hot water flow rate, the energy loss is merely less than $8 \%$.

Similarly to most existing industrial parks in the world, the construction period of the Eco-Park was too long, resulting in changes between the early planning and the post-construction period, which greatly impacted the economy of the project. Viewing this, it becomes clear that the deviation of each stage would affect the specific economic benefit of the whole project.

Table 6 Predicted results of the Sino-German Eco-Park

\begin{tabular}{lll}
\hline No. & Technical indicator & Value \\
\hline 1 & Million in GDP comprehensive energy consumption, Tce/million yuan & 0.23 \\
2 & Million USD of carbon emission intensity, $\mathrm{tCO}_{2} /$ million USD & 220 \\
4 & Carbon emission reduction rate, $\%$ & 64.6 \\
5 & Clean energy utilization rate, $\%$ & 80.6 \\
6 & Renewable energy utilization rate, $\%$ & 20.6 \\
7 & Energy utilization efficiency, $\%$ & 80.8 \\
8 & Building energy-saving rate for residential and public building, \% \\
\hline
\end{tabular}


In addition, there exists another potential long-term risk, i.e., the long-term trend of energy prices in the EcoPark, including the energy prices of electricity, natural gas and heat/cold. The prices of the energy source are constrained by long-term contracts with end users, but the energy purchased from external enterprises, such as the national grid and gas company, were not included in the contract. These energy price changes would have a fatal impact on the cost of the long-term operation and maintenance of the entire DEN system project, directly determining whether it is profitable or not.

On the other hand, the gas, heat pipeline and power grid were all built ahead of the Eco-Park construction schedule according to the requirements of the local government in China, and the construction of heat, steam and natural gas pipelines networks had to conform to the government's plan. The initial investment of the project was usually high in the early stage, so the risk for the enterprise would also increase correspondingly. How to design the DEN system reasonably and provide a convincing reference for risk analysis of the investments remains an important topic for the projects of the Eco-Park.

\section{Conclusion and remarks}

This paper presents a new method to design a DEN system that integrates a city and urban industrial park planning and energy planning, and gives a high-level energy solution plan for a city or urban industrial parks.

A case study of the Sino-German Eco-Park was used to demonstrate the new design approach for the DEN system, which is the first regional DEN system with multienergy integration in China. Compared to the traditional concentrated and large-scale energy systems, the establishment of a DEN system did not only employ the advantages of renewable solar, wind and natural gas energy, but also used a ground source/water source heat pump, as well as energy storage with distributed energy technology. By adopting the advanced network control technology on the integrated management platform, it was able to realize a highly efficient energy production, operation and maintenance of the Eco-Park, which would also promote energy conservation and $\mathrm{CO}_{2}$ emission reduction.

Finally, the encountered problems, as well as the practical experience, were thoroughly summarized from the energy system planning through the design, construction and operation to the maintenance of the DEN system in the Sino-German Eco-Park, to offer lessons learned for future projects. There is a necessity to further evaluate the results of this innovative approach based on the future acquired operation data of the DEN system, so that it could provide the method, experience and technical support for similar projects in the future.

\section{Abbreviations}

HRSG: Heat recovery steam generators; CCHP: Combined cooling heating and power; CHP: Combined heat and power; DEN: Distributed energy network; DES: Distributed energy system; PV: Photovoltaic power; LNG: Liquefied natural gas; CNG: Compressed natural gas; NGCC: Natural gas and steamcombined cycle system.

\section{Acknowledgements}

The authors would like to thank the entire research team of 'National Key Basic Research Program of China' and Operations and Management Team of SinoGerman eco-park. Within this paper, the results of the original energy plan and the current development of the Sino-German Eco-Park is presented, whereas follow-up research is continuing.

\section{Authors' contributions}

XZ wrote most parts of the manuscript, performed the literature analysis, contributed to the system analysis according to his research experience, developed the concept of the indicators and identified them, and was mainly responsible for the discussion and conclusions sections. The others coordinated the data collection, data analysis and project support. All authors read and approved the final manuscript.

\section{Funding}

This work was financially supported by the National Key Basic Research Program of China (2014CB249200) "Basic research on a distributed energy network system which integrated renewable energy and natural gas".

Availability of data and materials

All data generated or analyzed during this study are included in this published article.

\section{Declarations}

Ethics approval and consent to participate

Not applicable.

\section{Consent for publication}

Not applicable.

\section{Competing interests}

The authors declare that they have no competing interests.

\section{Author details}

${ }^{1}$ College of Chemical Engineering and Environment, China University of Petroleum-Beijing, Beijing 102249, China. ${ }^{2}$ ENN Science \& Technology Ltd, Langfang 065001, China. ${ }^{3}$ China Petroleum Pipeline Engineering Company Ltd, Langfang 06500, China. ${ }^{4}$ School of Mechanical Engineering, Hebei University of Technology, Tianjin 300130, China. ${ }^{5}$ State Key Laboratory of Coal-Based Low-Carbon Energy, ENN, Langfang 065001, China.

Received: 18 July 2019 Accepted: 11 March 2021

Published online: 23 March 2021

\section{References}

1. Dai YD (2013) Energy Revolution: an interpretation of energy situation and development strategy. Electric Age 12:60-61

2. IRENA (2019) Global energy transformation: A roadmap to 2050 (2019 edition). International Renewable Energy Agency, Abu Dhabi. https:// www.irena.org/publications/2019/Apr/Global-energy-transformation-Aroadmap-to-2050-2019Edition

3. Ellabban O, Abu-Rub H, Blaabjerg F (2014) Renewable energy resources: current status, future prospects and their enabling technology. Renew Sustain Energy Rev 39:748-764. https://doi.org/10.1016/j.rser.2014.07.113

4. Jacobson MZ, Delucchi MA, Bazouin G et al (2015) 100\% clean and renewable wind, water, and sunlight (WWS) all-sector energy roadmaps 
for the 50 United States. Energy Environ Sci 8:2093-2117. https://doi.org/ 10.1039/C5EE01283J

5. Xu JZ (2002) Prospects of distributed power supply and combined cooling, heating and power. Energy Conserv Environ Protect 3:10-14

6. Jin HG, Sui J (2016) Transformational technology innovation—distributed energy system. Distributed Energy 1:1-5. https://doi.org/10.16513/j.cnki. 10-1427/tk.2016.01.002

7. Beccali M, Cellura M, Mistretta M (2003) Decision-making in energy planning. Application of the Electre method at regional level for the diffusion of renewable energy technology. Renewable Energy 28(13):2063-2087. https://doi.org/10.1016/S0960-1481(03)00102-2

8. Mourmouris JC, Potolias C (2013) A multi-criteria methodology for energy planning and developing renewable energy sources at a regional level: a case study Thassos Greece. Energy Policy 52(1):522-530. https://doi.org/ 10.1016/j.enpol.2012.09.074

9. Lund R, Mathiesen BV (2015) Large combined heat and power plants in sustainable energy systems. Appl Energy 142(15):389-395. https://doi. org/10.1016/j.apenergy.2015.01.013

10. Kopanos GM, Georgiadis MC, Pistikopoulos EN (2013) Energy production planning of a network of micro combined heat and power generators. Appl Energy 102:1522-1534. https://doi.org/10.1016/j.apenergy.2012.09. 015

11. Sperling K, Moeller B (2012) End-use energy savings and district heating expansion in a local renewable energy system - a short-term perspective. Appl Energy 92:831-842. https://doi.org/10.1016/j.apenergy.2011.08. 040

12. Kayo G, Hasan A, Siren K (2014) Energy sharing and matching in different combinations of buildings, CHP capacities and operation strategy. Energy Build 82:685-695. https://doi.org/10.1016/j.enbuild.2014.07.077

13. Keirstead J, Samsatli N, Shah N, Weber C (2012) The impact of CHP (combined heat and power) planning restrictions on the efficiency of urban energy systems. Energy 41(1):93-103. https://doi.org/10.1016/j.energy. 2011.06.011

14. Gu W, Wu Z, Bo R, Liu W, Zhou G, Chen W, Wu ZJ (2014) Modeling, planning and optimal energy management of combined cooling, heating and power microgrid: a review. Int J Electr Power Energy Syst 54:26-37. https://doi.org/10.1016/j.jiepes.2013.06.028

15. Liu X, Ye W, Gao B (2010) Eco-friendly municipal infrastructure planning with the idea of low-carbon-take the case of Sino-Singapore Tianjin eco-city. In: Proceedings of the international conference on urban development and planning 2010, Qinhuangdao, 2010.

16. Xu B, Zhou S, Hao L (2015) Approach and practices of district energy planning to achieve low carbon outcomes in china. Energy Policy 83:109-122. https://doi.org/10.1016/..enpol.2015.04.008

17. Sikder SK, Eanes F, Asmelash HB, Kar S, Koetter T (2016) The contribution of energy-optimized urban planning to efficient resource use - a case study on residential settlement development in Dhaka city. Bangladesh Sustainability 8(2):119-119. https://doi.org/10.3390/su8020119

18. Mirakyan A, De Guio R (2015) Modelling and uncertainties in integrated energy planning. Renew Sustain Energy Rev 46:62-69. https://doi.org/10. 1016/j.rser.2015.02.028

19. Brandoni C, Polonara F (2012) The role of municipal energy planning in the regional energy-planning process. Energy 48(1):323-338. https://doi. org/10.1016/j.energy.2012.06.061

20. Neves AR, Leal V (2010) Energy sustainability indicators for local energy planning: review of current practices and derivation of a new framework. Renew Sustain Energy Rev 14(9):2723-2735. https://doi.org/10.1016/j. rser.2010.07.067

21. Amado M, Poggi F, Amado AR (2016) Energy efficient city: a model for urban planning. Sustain Cities Society 26:476-485. https://doi.org/10. 1016/j.scs.2016.04.011

22. Hukkalainen M, Virtanen M, Paiho S, Airaksinen M (2017) Energy planning of low carbon urban areas - examples from Finland. Sustainable Cities and Society 35:715-728. https://doi.org/10.1016/j.scs.2017.09.018

\section{Publisher's Note}

Springer Nature remains neutral with regard to jurisdictional claims in published maps and institutional affiliations.
Ready to submit your research? Choose BMC and benefit from:

- fast, convenient online submission

- thorough peer review by experienced researchers in your field

- rapid publication on acceptance

- support for research data, including large and complex data types

- gold Open Access which fosters wider collaboration and increased citations

- maximum visibility for your research: over $100 \mathrm{M}$ website views per year

At BMC, research is always in progress.

Learn more biomedcentral.com/submissions 